\title{
Being Efficient to Stay Strong in a Weak Economy. The Case of Calabrian Manufacturing Firms
}

\author{
Francesco Aiello, Concetta Castiglione \\ Department of Economics, Statistics and Finance, University of Calabria, Campus di Arcavacata di Rende, \\ Cosenza, Italy \\ Email: francesco.aiello@unical.it, concetta.castiglione@unical.it
}

Received 13 March 2014; revised 13 April 2014; accepted 20 April 2014

Copyright (C) 2014 by authors and Scientific Research Publishing Inc.

This work is licensed under the Creative Commons Attribution International License (CC BY).

http://creativecommons.org/licenses/by/4.0/

(c) (i) Open Access

\begin{abstract}
The aim of this work is to study the efficiency of firms operating in Calabria, a small and economically-lagging Italian region. The analysis is carried out by estimating a stochastic production frontier for an unbalanced panel of manufacturing firms which are observed over the 1998-2006 period. Results show that the efficiency score is, on average, about $60 \%$. A declining trend is observed over the last three-year period, 2004-2006. Moreover, efficiency increases with firm age and when firms export. Inconclusive evidence is found for the role of investments in ICT and R\&D. This is not very surprising given that private effort in technological activities is extremely low in Calabria (private R\&D intensity was less than $0.075 \%$ of regional GDP in 2010).
\end{abstract}

\section{Keywords}

ICT, R\&D, Stochastic Frontier, Calabria, Manufacturing Firms

\section{Introduction}

The high heterogeneity in firm performance and the persistent regional productivity gaps are some of the most debated issues in Italy [1]-[4]. In the South of the country, the typical weaknesses of firms are exacerbated: they are, on average, much smaller than their counterparts in the Centre-North, exhibit a very low level of internationalization and underperform in every innovative activity [5]. Although firm agglomeration appears to have contributed to overcoming the effects of the recent crisis, evidence shows that spatial concentration of economic activity is common in northern regions and rare in the south [6].

Within this general framework, this work focuses on the efficiency of firms operating in Calabria, the least developed Italian region [7]. Compared to the southern regions, Calabria has the typical features of weak eco- 
nomies: a high degree of dependence on external public transfers; a low degree of internationalization; a weak innovative system; a fragile financial structure; widespread corruption. Just an example for all. When considering the regional innovation system, it emerges that in Calabria the investments in R\&D were, in 2010, 150 MLN of Euros, about $0.5 \%$ of regional GDP. In Italy this figure is equal to $1.53 \%$, about half of $3 \%$ target set for Italy by Europe 2020. Dramatic signals come also from the composition of Research and Development (R\&D) expenditure: in 2010, $85 \%$ of investments are made by universities. The differences between Calabria and the rest of Italy are therefore really worrying in the private-sector: when in Calabria firms spend 1 euro in R\&D, the counterparts in the north-west of Italy spend 11 euro. In short, Calabria is an interesting case-study because firms face a context that is poorly endowed in terms of external factors which act as stimulus and support for individual growth.

By following this line of reasoning, it becomes extremely interesting to analyze how Calabrian firms react to the absence of any type of positive territorial externality. They can act by adopting the best practices in order to be internally strong and efficient and overcome the diseconomies of being located in a poor economy. To this end, this work applies the Stochastic Frontier Approach (SFA) to measure the efficiency scores of an unbalanced panel data of Calabrian manufacturing firms observed over the 1998-2006 period. Efficiency is meant to be the distance from the regional production frontier, which we estimated by using the model specification proposed by [8]. Data are from the VIII, IX and X surveys carried out by Mediocredito Centrale-Capitalia (MCC) and Capitalia-UniCredit.

With regard the economic model used in the empirical setting, it is clear that efficiency gains are dependent on many factors, the most influent of which should be the Information and Communication Technologies (ICTs) and the R\&D efforts made by each company. In other words, it is expected that the introducing and adopting of technology will translate to a systemic increase in efficiency and productivity. For these reasons, our aim is to provide an analysis of the role exerted by some firm-specific factors which are meant to influence firms' efficiency directly. Basically, these are individual investments in ICT and R\&D. We also use the firm's openness to international markets, age and affiliation to corporate firms as other controlling factors. Estimations also allow for sectorial heterogeneity and time effect.

Results show that ICT and R\&D investments do not have any impact on the efficiency of Calabrian manufacturing firms. On the other hand, it is found that exporting activities and firm age have a positive effect on efficiency. We also find that technical efficiency (TE) is equal to almost $60 \%$ over the entire period, meaning that output can, in theory, be increased without changing the amount of any productive factor. On average, a $40 \%$ efficiency gain could be achievable just by optimizing the use of inputs. Moreover, efficiency is higher in the 1998-2003 sub-period and declines to 55\% in 2004-2006. Finally, when averaging TE by firm-group, it emerges that exporters perform better than non-exporters and that no statistically significant differences in mean exist between R\&D and non-R\&D performers and ICT and non-ICT adopter firms.

The remainder of this paper is structured as follows. Section 2 introduces the empirical setting, which encompasses the methodology, the economic model and the empirical approach used to evaluate efficiency. Section 3 briefly presents the dataset, while Section 4 focuses on the results. Some conclusions are presented in Section 5.

\section{The Empirical Setting}

A production frontier specifies the maximum output achievable by employing a combination of inputs. The distance between the production frontier and the actual output is meant to be a relative measure of a firm's technical inefficiency. A firm may be below the frontier and, thus, be inefficient or, alternatively, it may be on the production frontier and be efficient. In short, a technically inefficient firm could produce the same output with fewer inputs or use the same inputs to produce more output.

From an empirical perspective, several techniques have been used to estimate production frontiers. They may be classified as parametric and non-parametric and the choice of the method to be used has been the subject of great debate because each approach has its advantages and disadvantages [9]. The advantage of non-parametric methods (such as DEA, Data Envelopment Analysis) is that no assumption regarding the functional form is made. Furthermore, DEA does not require an explicit assumption about the distribution of the inefficiency term [10]. However, in DEA, the distance from the frontier is entirely due to TE. The fact that it does not take into account how randomness may explain part of the distance from frontier is the main limit to DEA. Indeed, if any measurement error and any other source of stochastic variation in the dependent variable is treated as part of the 
random error, then the estimated-efficiency scores will be biased and sensitive to outliers. This caveat is overcome by SFA which models the composite error structure with a 2-side symmetric component and 1-side term. Being a parametric method, SFA requires some assumptions about (a) the functional form to be assigned to the frontier and (b) the distribution proprieties of two components of the composite error. As far as the first assumption is concerned, we consider a Cobb-Douglas production frontier as it satisfies the basic requirements (quasi-concavity and monotonicity) for production frontiers, although it considers a unitary elasticity of substitution. Finally, we follow the literature with regard the distributions to be assigned to the two components of the error (see below). A further advantage of SFA derives from the specification proposed by [8], in which the frontier model and the inefficiency equation are simultaneously estimated. Thus, in terms of consistency, SFA is an improvement upon previous two-step modelling where one firstly estimated inefficiency using a frontier and, secondly, used the estimated efficiency-score as the dependent variable in subsequent regression ${ }^{1}$ [11].

Following [13]-[15], the Cobb-Douglas production function we use is specified (in logs) as follows:

$$
\ln Y_{i t}=\beta_{0}+\beta_{1} \ln K_{i t}+\beta_{2} \ln L_{i t}+\beta_{3} \ln M_{i t}+\beta_{4} P A V_{1 i}+\beta_{5} T+v_{i t}-u_{i t}
$$

where $Y_{i t}$ is the output of the $i$-th firm at time $t(i=1,2, \cdots, N$ and $t=1,2, \cdots T) ; K$ is the capital, $L$ the labor, $M$ the raw materials ${ }^{2}$. The variable $P A V_{1}$ is a dummy which takes the value 1 if it belongs to traditional sectors (Pavitt 1$)^{3}$ and zero otherwise, while $T$ is a time-trend. The random error $v_{i t}$ is assumed to be independent and identically distributed (i.i.d.) with zero mean and constant variance $N\left(0, \sigma_{v}^{2}\right)$, while $u_{i t}$ represents the component of independently (but not identically distributed) non-negative random variables. Under the assumption of normality, $u_{i t}$ is distributed as $N\left(\mu, \sigma_{\mu}^{2}\right)$. Efficiency is the conditional expectation of $\exp \left(-u_{i}\right)$.

Beside allowing decomposition of the composite error, another advantage of SFA relates to the possibility to investigate the determinants of firms' efficiency. In this work, investments in ICT and in R\&D, exports, age and affiliation to a corporate firms are the explicative variables used to explain the efficiency of Calabrian firms. Hence, the inefficiency equation is as follows:

$$
-u_{i t}=\alpha_{0}+\delta_{1} I_{C T}+\delta_{2} R \& D_{i t}+\delta_{3} \exp _{i t}+\delta_{4} a g e_{i t}+\delta_{5} \text { group }_{i t}+\varepsilon_{i t}
$$

where ICT is a dummy variable which is 1 if the firm invested in ICT at time $t$ and zero otherwise, $R \& D$ takes the value 1 if firm invest in R\&D activities at time $t$ and zero otherwise, exp represents a dummy variable that is equal to unity if firm exports at time $t$ and zero otherwise, age is the age of the firm, and group indicates whether a firm is affiliated to corporate firms at time $t$, and zero otherwise.

The expected signs for all the coefficients of Equation (1) are positive: each input factor positively contributes to production. As for inefficiency, the evidence of the impact of ICT on firm performance was mixed until the mid-1990s, when [19] showed that ICT has a substantial effect on firm productivity levels. In our case, if the $\delta_{1}$ coefficient is negative, then ICT will exert a favorable effect on technical efficiency. The same applies for R\&D expenses: the sign is expected to be negative, given that it is widely argued that R\&D efforts would increase firm efficiency. It is expected that firms involved in exporting activity will have a positive role, assuming that firms which face international competition are more efficient than the others. A positive relationship between age and efficiency can be expected due to "learning by doing" processes, which occur through production experience. Evidence of this for Italy is in [15] [18]. However, others show that younger firms generally adopt new innovation easily, while older firms delay adoption as it may be too costly to substitute old methods, thus implying that efficiency may decrease with age [13]. Finally, the expected sign of the coefficient associated to group is negative. In other words, TE is higher for firms belonging to groups: large organizations have relatively higher productivity and competitiveness than individual firms [14].

However, it is very interesting to verify whether all these expectations hold in the case of firms operating in Calabria, where the industry comprises small and independent companies which rarely invest in technological equipment and have little penetration to international markets.

\footnotetext{
${ }^{1}$ The two-step approach suffers from the fact that inefficiency is assumed to be identically and independently distributed in the main frontier equation, while, in practice, it depends on other variables in the inefficiency equation [12].

${ }^{2}$ The output is measured by the value of firm sales, labour is represented by the number of employees, while the physical capital is gauged by the sum of fixed and immaterial assets. These choices are widely shared by scholars using firm-data level and, especially, by those referring to the same data-source [14]-[18].

${ }^{3}$ In the Pavitt taxonomy, sectors are classified as supplier dominated (Pavitt 1), scale intensive (Pavitt 2), specialized supplier (Pavitt 3) and science based (Pavitt 4).
} 


\section{Variables and the Sample of Firms}

Data used in this analysis are from the VIII (1998-2000), IX (2001-2003) and X (2004-2006) surveys of Italian manufacturing firms carried out by the MCC and Capitalia-UniCredit. The firms located in Calabria are extracted from the original three datasets ${ }^{4}$.

Table 1 displays some descriptive statistics of the sample of the Calabrian firms reported in the three surveys analyzed. In particular, it presents the distribution of firms and labor productivity by firm-group. Firms are grouped into firms that invest in ICT, firms that invest in R\&D, firms that export and firms affiliated to corporate firms.

The sample is comprised of 193 firm-observations. Of the whole sample, 47\% of the firms invest in ICT, 44\% invest in R\&D, 25\% export and 16\% are affiliated to corporate firms. Furthermore, it is possible to see that, in 1998-2000, there were 48 firms in Calabria investing in ICT. In the successive period, there were 24, while there were 19 Calabrian firms investing in ICT from 2004 to 2006. With regard to R\&D performers, 42 firms invested over the period 1998-2000, 7 during the second period (2001-2003) and 36 in the last one. 15 firms out of 57 present in the VIII survey exported in the 1998-2000 three-year period, 21 (out of 44) exported in the 2001-2003 period and 13 (out of 92) during the last period. Finally, 7, 12 and 11 firms are affiliated to corporate firms in the VIII, IX and X surveys, respectively. The lower part of Table 1 shows the number of firms that did not invest in ICT, firms that did not invest in R\&D, firms that did not export and firms that are not affiliated to corporate firms.

Table 1, also, reports the labor productivity (in logs). From the whole sample, it can be noted that labor productivity is highest for firms that exported, while productivity is lowest for firms that invested in ICT.

\section{Results and Discussion}

The estimated results of the stochastic production frontier are displayed in Table 2. In what follows, we proceed by firstly presenting some diagnostics of the model and then comment the estimations obtained from the frontier and the inefficiency Equations. The final focus is on the efficiency scores averaged by year and firm-group.

With reference to the model, one significant result regards gamma, which is the ratio between the variance of inefficiency and the variance of the composite error. For ease of exposition, let's consider the Model 2. The

Table 1. Number of Calabrian firms surveyed.

\begin{tabular}{|c|c|c|c|c|c|c|c|c|c|c|c|c|}
\hline & \multicolumn{3}{|c|}{ 1998-2000 survey } & \multicolumn{3}{|c|}{ 2001-2003 survey } & \multicolumn{3}{|c|}{ 2004-2006 survey } & \multicolumn{3}{|c|}{ All surveys } \\
\hline & $Y / L$ & $\begin{array}{l}\text { Number } \\
\text { of firms }\end{array}$ & $\begin{array}{l}\% \text { of } \\
\text { firms }\end{array}$ & $Y / L$ & $\begin{array}{l}\text { Number } \\
\text { of firms }\end{array}$ & $\begin{array}{l}\% \text { of } \\
\text { firms }\end{array}$ & $Y / L$ & $\begin{array}{l}\text { Number } \\
\text { of firms }\end{array}$ & $\begin{array}{l}\% \text { of } \\
\text { firms }\end{array}$ & $Y / L$ & $\begin{array}{l}\text { Number } \\
\text { of firms }\end{array}$ & $\begin{array}{l}\% \text { of } \\
\text { firms }\end{array}$ \\
\hline Firms that invested in ICT & 4.52 & 48 & 84.21 & 5.05 & 24 & 54.55 & 4.70 & 19 & 20.65 & 4.70 & 91 & 47.15 \\
\hline Firms that invested in R\&D & 4.54 & 42 & 73.68 & 4.77 & 7 & 15.91 & 5.08 & 36 & 39.13 & 4.78 & 85 & 44.04 \\
\hline Firms that exported & 4.97 & 15 & 26.32 & 5.24 & 21 & 47.73 & 5.23 & 13 & 14.13 & 5.15 & 49 & 25.39 \\
\hline Firms affiliated to corporate firms & 5.10 & 7 & 12.28 & 4.87 & 12 & 27.27 & 4.38 & 11 & 11.96 & 4.74 & 30 & 15.54 \\
\hline Firms that did not invest in ICT & 5.21 & 9 & 15.79 & 5.10 & 20 & 45.45 & 5.06 & 73 & 79.35 & 5.08 & 102 & 52.85 \\
\hline Firms that did not invest in R\&D & 4.88 & 15 & 26.32 & 5.13 & 37 & 84.09 & 4.93 & 56 & 60.87 & 4.99 & 108 & 55.96 \\
\hline Firms that did not export & 4.51 & 42 & 73.68 & 4.92 & 23 & 52.27 & 4.95 & 79 & 85.87 & 4.81 & 144 & 74.61 \\
\hline \multirow[t]{2}{*}{$\begin{array}{l}\text { Firms that are not affiliated to } \\
\text { corporate firms }\end{array}$} & 4.56 & 50 & 87.72 & 5.15 & 32 & 72.73 & 5.07 & 81 & 88.04 & 4.93 & 163 & 84.46 \\
\hline & & $N$. & $\%$ & & $N$. & $\%$ & & $N$. & $\%$ & & $N$. & $\%$ \\
\hline Observations & & 57 & 29.53 & & 44 & 22.79 & & 92 & 47.66 & & 193 & 100 \\
\hline
\end{tabular}

Note: $Y / L$ is labor productivity.

${ }^{4}$ The survey covers a sample of firms with 11 - 500 employees and all firms with more than 500 employees. It provides a great deal of information about the production and financial indicators of Italian manufacturing firms. The sample is stratified according to industry, geographical and size. The database contains questionnaire information regarding the individual firms' structure and behaviour, 3 years of balance sheet data, employees' education, age of the firm, turnover, etc. 
Table 2. Stochastic Cobb-Douglas production frontier and the inefficiency equation for a sample of Calabrian firms. ML Estimates over the Period 1998-2006.

\begin{tabular}{|c|c|c|c|c|c|c|}
\hline & \multicolumn{3}{|c|}{ Model 1} & \multicolumn{3}{|c|}{ Model 2} \\
\hline & Estimates & Std. Err. & z-values & Estimates & Std. Err. & z-values \\
\hline \multicolumn{7}{|c|}{ Panel A: production frontier } \\
\hline Constant & $4.72^{* * *}$ & 0.36 & 13.30 & $4.84^{* * * *}$ & 0.38 & 12.84 \\
\hline $\ln (\mathrm{K})$ & $0.25^{* * *}$ & 0.05 & 5.27 & $0.21^{* * *}$ & 0.05 & 4.21 \\
\hline $\ln (\mathrm{L})$ & $0.56^{* * *}$ & 0.15 & 3.74 & $0.69^{* * *}$ & 0.15 & 4.62 \\
\hline $\ln (\mathrm{M})$ & 0.05 & 0.12 & 0.44 & -0.04 & 0.13 & -0.30 \\
\hline$P A V_{1}$ & 0.04 & 0.10 & 0.42 & 0.11 & 0.10 & 1.13 \\
\hline $\mathrm{T}$ & 0.01 & 0.02 & 0.61 & 0.03 & 0.02 & 1.34 \\
\hline \multicolumn{7}{|l|}{ Panel B: inefficiency model } \\
\hline Exp & $-4.27^{*}$ & 2.42 & -1.76 & $-1.54^{*}$ & 0.80 & -1.93 \\
\hline Group & 1.53 & 1.01 & 1.51 & 0.15 & 0.43 & 0.34 \\
\hline ICT & 0.32 & 0.78 & 0.41 & & & \\
\hline $\mathrm{R} \& \mathrm{D}$ & 0.44 & 0.64 & 0.67 & & & \\
\hline Age & $-0.14^{*}$ & 0.09 & -1.67 & & & \\
\hline Young R\&D-ICT & & & & 0.78 & 1.02 & 0.71 \\
\hline Young ICT & & & & $1.81^{* * *}$ & 0.40 & 4.57 \\
\hline Young R\&D & & & & -0.76 & 1.02 & -0.71 \\
\hline Old R\&D-ICT & & & & -0.09 & 0.48 & -0.19 \\
\hline Old ICT & & & & $-1.86^{* *}$ & 0.85 & -2.18 \\
\hline Old R\&D & & & & $0.67^{* *}$ & 0.32 & 2.10 \\
\hline$\sigma^{2}$ & $1.836^{* *}$ & 0.64 & 2.87 & $0.9^{* * *}$ & 0.18 & 5.06 \\
\hline$\gamma=\sigma_{\mu}^{2} / \sigma^{2}$ & $0.886^{* * *}$ & 0.05 & 18.39 & $0.8^{* * * *}$ & 0.08 & 10.46 \\
\hline$L R(u=0)$ & 56.72 & & & 62.78 & & \\
\hline$L R\left(\delta_{i}=0\right)$ & 71.21 & & & 77.13 & & \\
\hline Number of firms & 55 & & & 55 & & \\
\hline Observations & 193 & & & 193 & & \\
\hline Technical efficiency & 0.65 & & & 0.61 & & \\
\hline
\end{tabular}

Source: see Table 1. Signif. Codes: ${ }^{* * *}=0.01 ;^{* *}=0.05 ;{ }^{*}=0.1$.

estimated gamma is 0.8 , indicating that $80 \%$ of the variability in the distance from the frontier is due to inefficiency. While inefficiency plays a dominant role in explaining distance variability, the evidence also implies that the remaining $20 \%$ of the total variance is due to the random component of the composite error. This would have been left out of the evaluation if we had modelled the production frontier through a deterministic frontier and, in so doing, we would have mis-estimated the role of inefficiency. Further evidence in favour of the empirical strategies which we follow is that provided by using the Likelihood Ratio test (LR) to verify the correct model specification of SFA. A first application of the LR is to test the presence of inefficiency: under Ho we have that $\mathrm{u}=0$. If this hypothesis is accepted, then the frontier may be estimated using OLS. For Model 2, results indicate that the LR-statistics is 62.75 and, therefore, Ho is rejected, meaning that the inefficiency is in the 
data and SFA is the method to be used. Similar conclusions can be drawn from Model 1. Another LR test is carried out by imposing under Ho that inefficiency of the all parameters in Equation (2) are equal to zero. In other words, we test whether inefficiency is not explained by the set of z-statistics included in Equation (2). The degrees of freedom are given by the number of regressors in the inefficiency equation and the critical values are tabulated in [20]. For Model 2, we find that LR is 77.13 and, thus, we reject the null hypothesis at a high level of significance (the critical value at $1 \%$ is just 19.38). This implies that the choice to use the SFA specification à la Battese and Coelli is supported by our data.

As far as the estimations obtained from the production frontier are concerned (panel A of Table 2), it should be pointed out that the output elasticities to capital and labor are significantly positive, confirming the important contribution to production of traditional inputs. In addition, the magnitude of their impact is broadly coherent with expectation (output elasticity to capital is 0.21 , while labor elasticity is about 0.69 ). With regard the raw materials coefficient, results show no statistical significance. We have also tested that the sum of elasticities is statistically less than unity and, thus, the production frontier exhibits decreasing returns to scale. Furthermore, data in Table 2 highlight that the technology of Calabrian firms in traditional industries (Pavitt 1) does not differ from that used in other industries ${ }^{5}$. Finally, the coefficient associated to time-trend is positive, but not significant, indicating that there was no frontier movement over the period under scrutiny.

Something that is immediately evident from the inefficiency model is that results are mixed (Table 2, panel B). When considering Model 1 (Table 2), it emerges that efficiency of Calabrian firms is positively related to exports, since the parameter associated to the dummy variable exp is negative and significant at the $10 \%$ level. Another significant impact on efficiency comes from firm age: we find that TE increases with age. Moreover, membership of a large organization does not exert any influence on firms' efficiency. This is also true for investments in ICT and, so, contrasts with the literature on the role of ICT [10] [15] [18] [21]. The coefficient associated with the R\&D dummy is also positive, but not significant, implying that R\&D does no exert any effect on the efficiency of Calabrian firms. This finding also contrasts with the previous literature (see, for example, [22]).

What clearly emerges from Model 1 are the contrasting results regarding the role of innovation and of investments in ICT. Given this, we explore the links between TE and the technological factors (ICT and R\&D), proposing a further disaggregation of firms on the basis of age and the status as innovators in ICT and/or in $\mathrm{R} \& \mathrm{D}$. To this end, firms are meant to be young if they are less than 10 years (firms aged more than 10 years are considered old). Within each group, we distinguish between firms, which only invest in R\&D (Young R\&D and Old R\&D), only in ICT (Young ICT and Old ICT) and both in ICT and R\&D (Young ICT-R\&D; Old ICT-R\&D). Results are in Table 2. The evidence found is not such as to allow a single conclusion. Firm inefficiency is positively linked to the status of being a young-ICT performing firm (the estimated parameter is indeed positive, 1.81, and highly significant). The same applies for the sample of old and R\&D firms: in this case, the parameter is 0.67 and significant at $5 \%$ level. Efficiency appears to be strongly related to the status of being an old and ICT performer (the estimated coefficient is -1.86). As for the groups of young-R\&D and old R\&D-ICT firms, we find a positive impact on efficiency, but the evidence remains inconclusive because the estimated parameters are not significant.

In contrast with previous literature (see, above all, [22]), from our results it emerges that there is no complementary effect between ICT and R\&D investments. This might be due to the features of Calabria, which appears to be still stuck to the Solow paradox. Indeed, immediately after the [23] assertion, some authors [11] [19] argue that ICTs were (and, likely, still are in economies such as Calabria) modest as share of aggregate stock of capital and that the diffusion of ICT and the absorption of its benefits take a long time to have discernible effects on firm performance. These arguments seem hold in our study. Indeed, a positive impact of ICT on efficiency has been revealed only for the old-ICT performers ${ }^{6}$.

With reference to the estimated TE scores, the first result to be discussed is that Calabrian firms achieved, on average, 65\% (Model 1) or 61\% (Model 2) of their potential production over the period 1998-2006. Hence, the increase in output that would have been possible without employing more inputs varies from $35 \%$ to $39 \%$

\footnotetext{
${ }^{5}$ The small number of firms (Table 1) imposes to group firms belonging to the scale intensive (Pavitt 2), specialised supplier (Pavitt 3 ) and science based (Pavitt 4) sectors. In all regressions the controlling group comprises firms of supplier dominated sector (Pavitt 1).

${ }^{6}$ The evidence reported in this paper is also in line with the earliest studies showing no relationship between ICT investment and firm performances. See, on this [24]. However, some caution should be made when interpreting our results. Due to the slackness of our dataset, we use only dummy variables to gauge firms' effort in ICT and R\&D activities. This would have deserved more attention, having had the availability of ICT and R\&D investments.
} 
(Table 2).

From a dynamic perspective, what we see from Figure 1 is that TE of Model 2 was 61\% in 1998 and increased to $72 \%$ in 2002, while it reached its minimum (50\%) in 2004 and, after, increased to about $55 \%$ in the two-year period 2005-2006. The same pattern is found when considering the TE retrieved from Model 1. Whatever the case, according to our estimations, Calabrian firms reduced their efficiency of production in the years immediately preceding the 2008 financial crisis and this may partly explain the collapse of entrepreneurship that many observers record in Italy in general and in the poorest Southern regions in particular during the crisis [6]. When the crisis started, the low levels of efficiency impeded Calabrian firms from reorganizing their production processes to cope with the exogenous-effects of the crisis.

Valuable information can be also retrieved by averaging the TE scores by firm-type. Figure 2 indicates that, for the 1998-2006 period, the exporting firms attain a TE score of about 75\%, while the TE for no-exporters is $55 \%$. When testing the equality of means, we obtain a p-value equal to 1 , indicating that exporters, on average, perform significantly better than non-exporters. It also emerges that firms which are part of a larger organization are, on average, $62 \%$ efficient, while the TE of independent firms is $59 \%$. However, the difference in means is not significant in this case. No difference is found when comparing R\&D and non-R\&D firms, whose TE has been estimated at around $60 \%$. Similarly, when dividing the sample according to the technological efforts in ICT, the evidence indicates that TE is, on average, $60 \%$. Importantly, it seems that older Calabrian firms perform better than the new ones as their TE is $64 \%$ and $51 \%$ respectively (the difference is highly significant, the $t$-values of the test on the equality of differences is 4.26). This evidence complements what was referred to above during the discussion on the estimated parameters of the inefficiency equation (Table 2).

What we have learnt is that, on average, the TE does not differ between R\&D (ICT) performers and non-R\&D (non-ICT) performers. At the same time, we see that the young firms achieved a significantly lower TE score than that obtained by the older ones. This merits further investigation. As before, we investigate whether some differences in averaged-TE exist for R\&D and/or ICT performers when they are grouped on the basis of age. Results are in Figure 3. Among the group of young-firms, the best performers are those that only invest in R\&D: their TE is $70 \%$. On the other hand, young firms that only invest in ICT achieve an extremely low TE (21\%): given the inputs they use, their output would increase by about $79 \%$ by just pursuing efficient strategies and

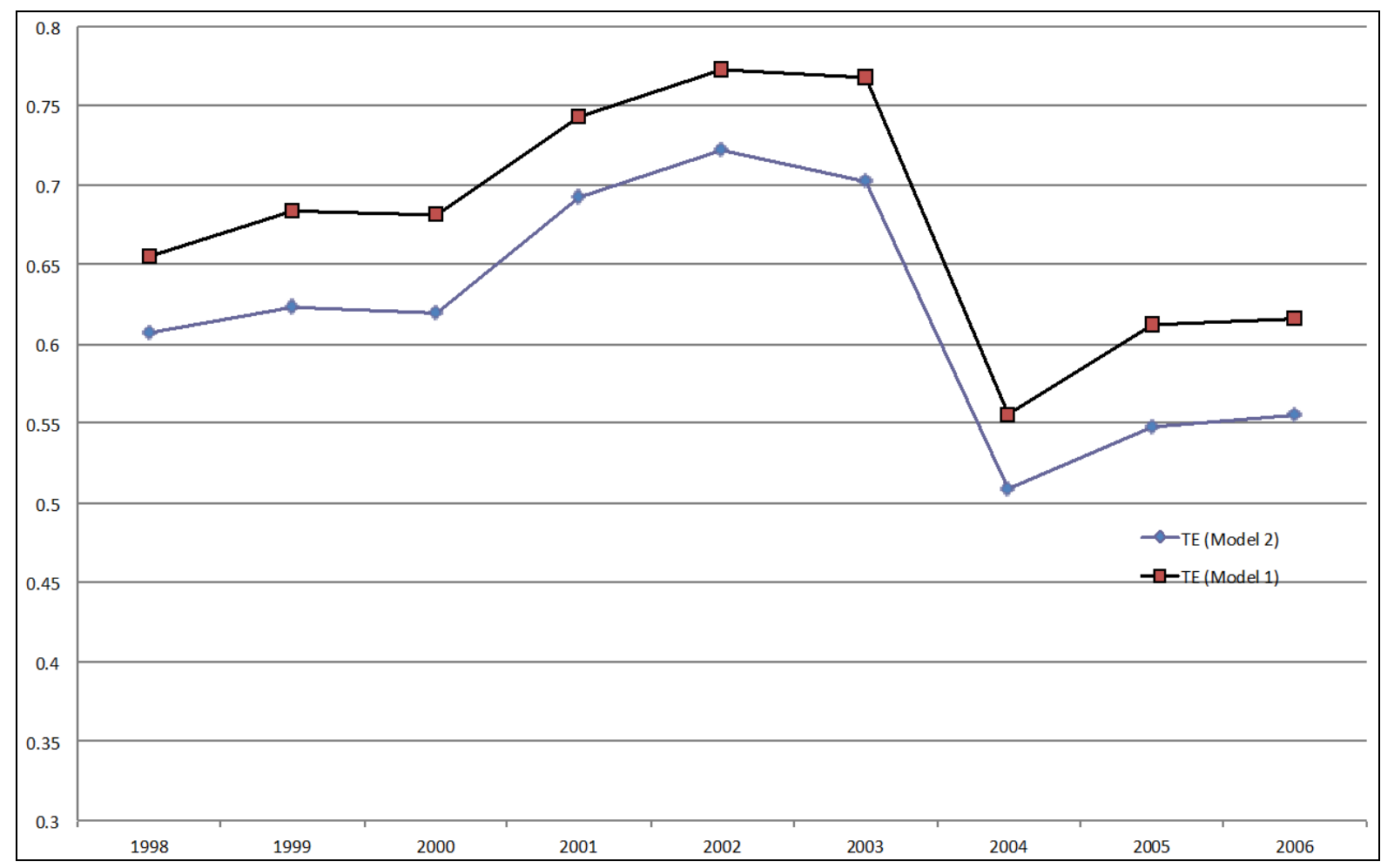

Figure 1. Technical efficiency of Calabrian firms over the period 1998-2006. 


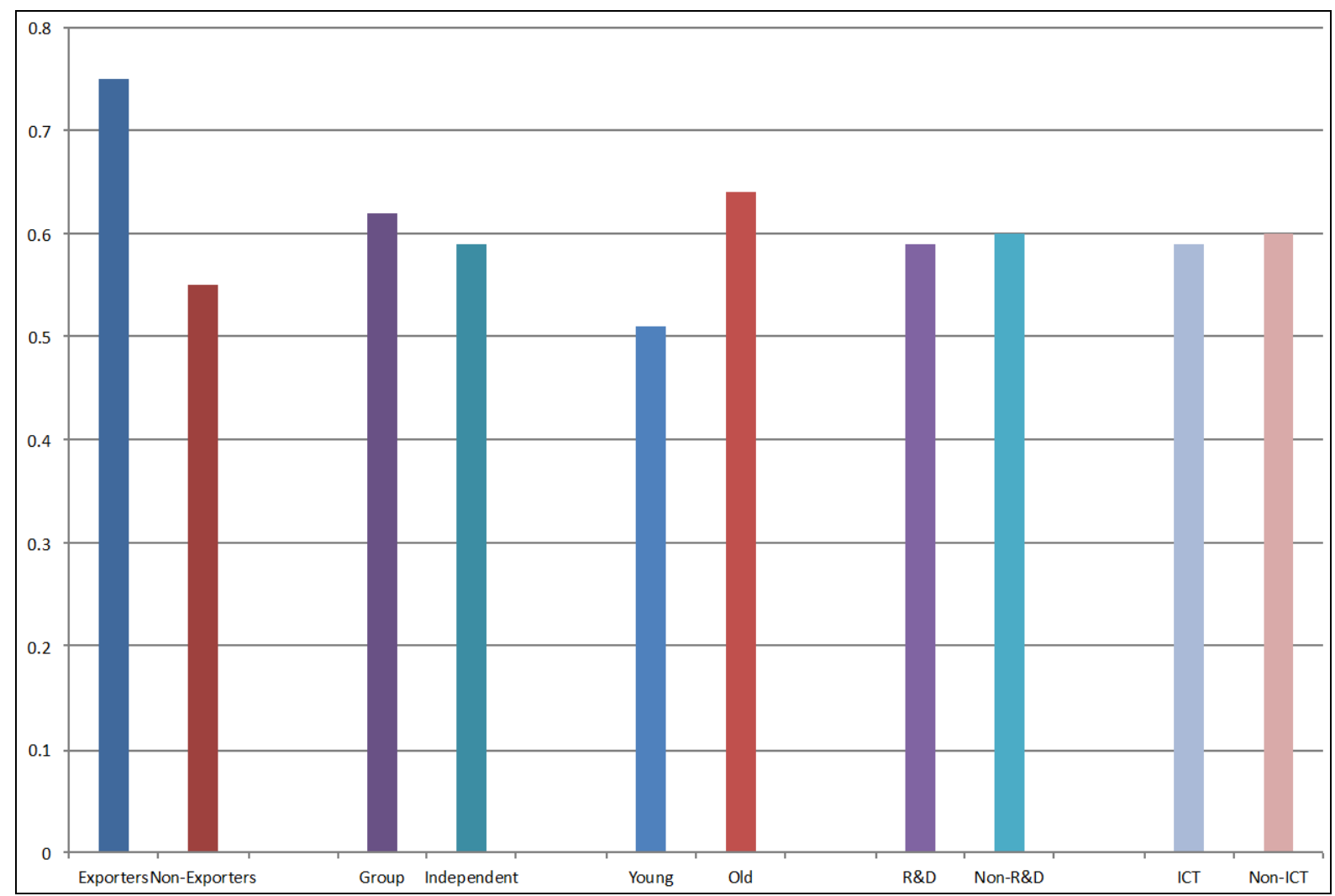

Figure 2. Technical efficiency of Calabrian manufacturing firms over the period 1998-2006. Average values by firmgroup.

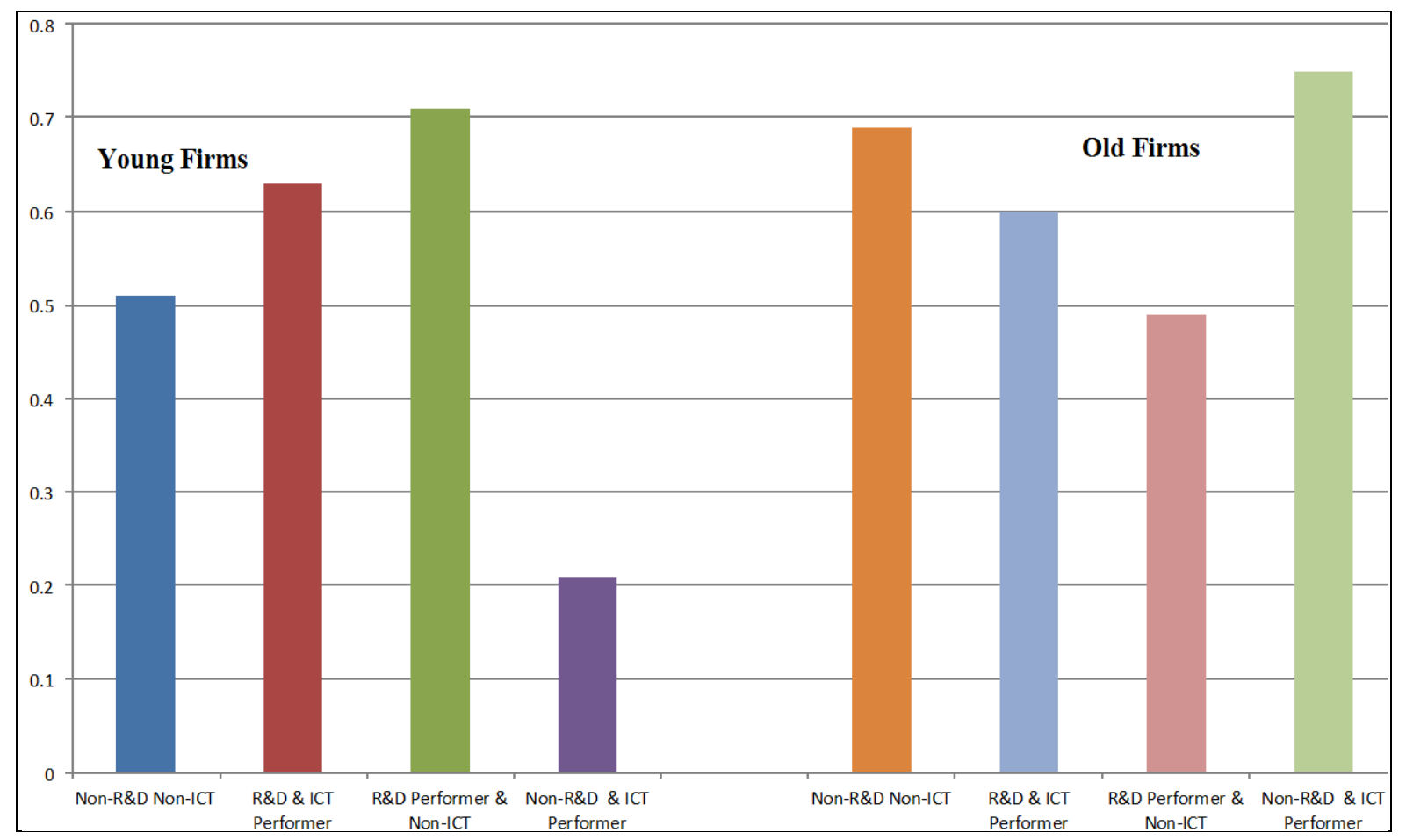

Figure 3. Technical efficiency of Calabrian manufacturing firms over the period 1998-2006. Average values for young and old R\&D-ICT performers. 
using the productive factors better. The evidence slightly differs when considering the old firms. In this case, the highest TE value (75\%) is observed for companies which only invest in ICT. It is worth underlining that a TE score of $75 \%$ is comparable to that (69\%) registered by old firms which neither invest in R\&D nor in ICT. Another outcome to be discussed concerns the R\&D and ICT performers: these have a TE of about $60 \%$, a value which does not vary according to firm age. In short, the main conclusion that may be drawn is that the initial result in favors of old firms (Figure 2) is due to these firms' only investing in ICT: they perform much more better than their counterparts in the group of young companies. Conversely, in all the other cases, TE in the young and old groups are comparable.

\section{Concluding Remarks}

This work estimates a production frontier of a sample of manufacturing firms operating in Calabria. This is done in order to measure the level of average efficiency and evaluate the role played by the main determinants of individual performance. To this end, a stochastic frontier approach—following the specification proposed by [8] — has been employed considering an unbalanced panel data extracted from the VIII, IX and X surveys by the MCC and Capitalia-UniCredit. In total, there are 193 firm-observations from 1998 to 2006. Three main results emerge.

First of all, this study confirms the role of traditional inputs (physical capital and labor) in determining the level of production in Calabria. While the size of output elasticity to labor is similar to the input-share in output predicted by earlier neoclassical models (one-third to physical capital and two-thirds to labor), the output-elasticity to capital is less than that expected. Thus, we find that the technology used in Calabria exhibits decreasing returns to scale.

Secondly, the estimated value of mean efficiency is also of great interest. It emerges that TE is around $60 \%$ with a declining trend over the years 2004-2006. According to our estimates, regional output could theoretically be increased by about $40 \%$ without increasing the amount of inputs used in production. Achieving this output-target could be possible by simply improving efficiency in each and every firm.

Finally, we find that efficiency increases with age, suggesting that a learning-by-experience effect is at work. The same holds for openness to international markets: exporters perform better and self-select into the world market as suggested by, among many others, [25] [26]. Inconclusive evidence is found for affiliation to corporate firms. On the other hand, contrasting outcomes have been found for firms investing in ICT and for those involved in R\&D. These efforts do not affect individual outcome and, so, no significant difference in averagedefficiency scores has been revealed when comparing firms in terms of the innovative activities they perform.

Undoubtedly, this latter finding is counterintuitive given that R\&D and ICT are two key sources of firmgrowth. Some facts may be used to explain this evidence. On the one hand, the number of innovating companies is extremely low in Calabria. This is verified in our data (see Table 1). If there are few innovators and these do not cooperate each other, then the spatial diffusion of knowledge will be restricted and productivity and technological spillovers will be limited. This means that firms will not be able to benefit from simply adopting the technology made by others and from economies of agglomeration, as proved by many authors [27]-[31]. On the other hand, we know that innovators are not only limited in number, but that the investments they make are small in scale. Firms invest rarely and when they do, the expenditures they make are low. In such cases, it is unlikely that ICT and R\&D will spontaneously stimulate productivity. As a consequence of this market-failure, a massive and selective policy aimed at fostering the use and diffusion of new knowledge is needed. Along this line of reasoning, this paper allows a clear, evidence-based policy implication to be drawn. Indeed, we have argued that Calabrian firms might produce more just by optimizing the use of inputs already available. Therefore, priority should be given to reducing firms' distance from the actual technological frontier. This could be easily pursued through improvements in decision-making, which basically are related to a host of variables including knowledge, experience and education and to the introduction of organization innovations. A regional policy that supports such processes will allow companies the possibility to acquire efficiency and could lead to (according to our evidence) an increase of up to $40 \%$ in regional production. Given that movement towards the frontier is easier to achieve than an upward shift in the frontier itself, a recovery of efficiency would generate wide and systemic benefits and, thus, alleviate, in a very short time, the negative impact of the current economic crisis.

\section{Acknowledgements}

This work has benefited from the financial support from Regione Calabria within the CALCOM project on "Re- 
gional Competitiveness and Innovation” (L.R. 10/1998).

\section{References}

[1] Aiello, F., Pupo, V. and Ricotta, F. (2014) Explaining Total Factor Productivity at Firm Level in Italy: Does Location Matter? Spatial Economic Analysis, 9, 1-20. http://dx.doi.org/10.1080/17421772.2013.863428

[2] Brida, J.G., Garrido, N. and Mureddu, F. (2014) Italian Economic Dualism and Convergence Clubs at Regional Level. Quality and Quantity, 48, 439-456. http://dx.doi.org/10.1007/s11135-012-9779-z

[3] Gitto, S. and Mancuso, P. (2013) The Contribution of Physical and Human Capital Accumulation to Italian Regional Growth: A Nonparametric Perspective. Journal Productivity Analysis, Online First.

[4] Mastromarco, C. and Woitek, U. (2006) Public Infrastructure Investment and Efficiency in Italian Regions. Journal of Productivity Analysis, 25, 57-65. http://dx.doi.org/10.1007/s11123-006-7127-9

[5] Pompei, F. (2013) Efficiency and Productivity Growth across the Italian Regions: The Regional Divide Revisited. MPRA Paper No. 52052.

[6] Bank of Italy (2013) The Industrial System in the South of Italy and the Crisis (L'industria meridionale e la crisi). Questioni di Economia e Finanza, Rome, 194.

[7] Svimez (2013) Rapporto SVIMEZ sull’economia del Mezzogiorno 2012. Il Mulino, Rome.

[8] Battese, G.E. and Coelli, T.J. (1995) A Model for Technical Efficiency Effect in a Stochastic Frontier Production Functions for Panel Data. Empirical Economics, 20, 325-332. http://dx.doi.org/10.1007/BF01205442

[9] Coelli, T. (1995) Recent Development in Frontier Modelling and Efficiency Measurement. Australian Journal of Agricultural Economics, 39, 219-245.

[10] Shao, B.B.M. and Lin, W.T. (2002) Technical Efficiency Analysis of Information Technology Investments: A TwoStage Empirical Investigation. Information and Management, 39, 391-401.

http://dx.doi.org/10.1016/S0378-7206(01)00105-7

[11] Greene, W.H. (1993) The Econometric Approach to Efficiency Analysis. In Harold, O.F., Knox Lovell, C.A. and Schmidt, S.S., Eds., The Measurement of Productivity Efficiency: Techniques and Applications. Oxford University Press, New York, 92-250.

[12] Wang, H.J. and Schmidt, P. (2002) One-Step and Two-Step Estimation of the Effect of Exogenous Variables on Technical Efficiency Levels. Journal of Productivity Analysis, 18, 129-144. http://dx.doi.org/10.1023/A:1016565719882

[13] Assefa, A. and Matambalya, F.A.S.T. (2002) Technical Efficiency of Small and Medium-Scale Enterprises. Eastern Africa Social Science Research Review, 18, 1-29. http://dx.doi.org/10.1353/eas.2002.0007

[14] Becchetti, L., Londono-Bedoya, D.A. and Paganetto, L. (2003) ICT Investment, Productivity and Efficiency: Evidence at Firm Level Using a Stochastic Frontier Approach. Journal of Productivity Analysis, 20, 143-167. http://dx.doi.org/10.1023/A:1025128121853

[15] Castiglione, C. (2012) Technical Efficiency and ICT Investment in Italian Manufacturing Firms. Applied Economics, 44, 1749-1763. http://dx.doi.org/10.1080/00036846.2011.554374

[16] Aiello, F., Cardamone, P. and Pupo, V. (2005) Produttività e capitale tecnologico nel settore manifatturiero italiano. L'Industria, 1, 119-146.

[17] Bugamelli, M. and Pagano, P. (2004) Barriers to Investment in ICT. Applied Economics, 36, 2275-2286. http://dx.doi.org/10.1080/0003684042000270031

[18] Castiglione, C. and Infante, D. (2014) ICTs and Time-Span in Technical Efficiency Gains. A Stochastic Frontier Approach over a Panel of Italian Manufacturing Firms. Economic Modelling, Forthcoming.

[19] Brynjolfsson, E. and Hitt, L. (1996) Paradox Lost? Firm Level Evidence on the Returns to Information Systems Spending. Management Science, 42, 541-558. http://dx.doi.org/10.1287/mnsc.42.4.541

[20] Kodde, D. and Palm, F. (1986) Wald Criteria for Jointly Testing Equality and Inequality Restrictions. Econometrica, 54, 1243-1248. http://dx.doi.org/10.2307/1912331

[21] Gholami, R., Moshiri, S. and Lee, S.Y.T. (2004) ICT and Productivity of the Manufacturing Industries in Iran. Electronic Journal on Information System in Developing Countries, 19, 1-19.

[22] Hall, B.H., Lotti, F. and Mairesse, J. (2013) Evidence on the Impact of R\&D and ICT Investments on Innovation and Productivity in Italian Firms. Economics of Innovation and New Technology, 22, 300-328. http://dx.doi.org/10.1080/10438599.2012.708134

[23] Solow, R.M. (1987) We'd Better Watch out. New York Review of Books, 12, 36.

[24] Castiglione, C. and Infante, D. (2013) ICT as General Purpose Technologies. A Microeconometric Investigation on 
Italian Firms. International Journal of Trade and Global Markets, 6, 225-241. http://dx.doi.org/10.1504/IJTGM.2013.054851

[25] ISGEP (2008) Understanding Cross-Country Differences in Exporter Premia: Comparable Evidence for 14 Countries. Review of World Economics, 144, 596-635. http://dx.doi.org/10.1007/s10290-008-0163-y

[26] Wagner, J. (2007) Exports and Productivity: A Survey of the Evidence from Firm-Level Data. The World Economy, 30, 60-82. http://dx.doi.org/10.1111/j.1467-9701.2007.00872.x

[27] Aiello, F. and Cardamone, P. (2012) Regional Economic Divide and the Role of Technological Spillovers in Italy. Evidence from Micro-Data. Structural Change and Economic Dynamics, 23, 205-220. http://dx.doi.org/10.1016/j.strueco.2012.03.001

[28] Audretsch, D.B. and Feldmann, M.P. (2004) Knowledge Spillovers and the Geography of Innovation. In Henderson, J.V. and Thisse, J.K., Eds., Handbook of Regional and Urban Economics, Elsevier, Amsterdam, 2713-2739.

[29] Brulhart, M. and Mathys, N. (2008) Sectoral Agglomeration Economies in a Panel of European Regions. Regional Science and Urban Economics, 38, 348-362. http://dx.doi.org/10.1016/j.regsciurbeco.2008.03.003

[30] Carboni Oliviero, A. (2013) Spatial and Industry Proximity in Collaborative Research: Evidence from Italian Manufacturing Firms. The Journal of Technology Transfer, 38, 896-910. http://dx.doi.org/10.1007/s10961-012-9279-2

[31] Rosenthal, S. and Strange, W. (2004) Evidence on the Nature and Sources of Agglomeration Economies. In Henderson, J.V. and Thisse, J.K., Eds., Handbook of Regional and Urban Economics, Elsevier, Amsterdam, 2119-2171. 